\title{
ПРАВОВЫЕ МЕХАНИЗМЫ РЕГУЛИРОВАНИЯ ТРУДОВОЙ ЗАНЯТОСТИ В СССР В ПЕРИОД НОВОЙ ЭКОНОМИЧЕСКОЙ ПОЛИТИКИ
}

\author{
О. Ю. Павловская \\ Национальный исследовательский университет \\ "Высшая школа эконолики"
}

Поступила в редакцию 26 фревраля 2021 г.

\begin{abstract}
Аннотация: в 2021 г. исполняется 100 лет с начала введения в СССР новой эконолической политики (неп). Советское законодательство о занятости и защите населения от безработицы этого периода позволило накопить богатый опыт правового регулирования данной области общественных отношений. Но насколько востребован этот опьт сегодня? В даннол вопросе на помощь приходит историко-правовой анализ, выстраивающий определенную (в тол числе хронологическую) последовательность принятия и отлены политических решений в сфере регулирования занятости и установить преелственность отдельных норл, ставших отправной точкой в фборлировании совреленной систель законодательства о занятости населения.

Ключевые слова: новая эконолическая политика, биржа труда, безработица, индустриализация, пятилетка, наём рабочей силь, общественные работьь.
\end{abstract}

\begin{abstract}
New Economic Policy (NEP) in the USSR. The Soviet legislation on employment and protection of the population from unemployment of this period allowed to accumulate a rich experience of legal regulation of this area of public relations. But how much is this experience in demand today? In this matter, the historical and legal analysis comes to the rescue, building a certain (including chronological) sequence of the adoption and abolition of political attitudes in the field of employment regulation and establishing the continuity of individual norms that have become the starting point in the formation of the modern system of legislation on employment.
\end{abstract}

Key words: new economic policy, labor exchange, unemployment, industrialization, five-year plan, hiring of labor, public works.

Кризис военного коммунизма обусловил переход к новой экономической политике. Переход к нэпу ${ }^{1}$ принято ассоциировать со значительной экономической либерализацией. Новая экономическая политика привела к кардинальным переменам в правовой, политической и экономической политике РСФСР.

Прогрессивные в условиях того времени изменения произошли в том числе и в сфере трудовой занятости.

${ }^{1}$ Новая экономическая политика проводилась советской властью с 1921 по 1929 г. с целью вывести страну из экономического кризиса и придать толчок в развитии экономики и сельского хозяйства.

(C) Павловская О. Ю., 2021 
Огромное значение имело принятие нового КЗоТ, который отражал некоторую демократизацию общественной жизни и потребности нэпа.

Новый кодекс законов о труде был принят 4-й сессией ВЦИК девятого созыва 30 октября 1922 г. $^{2}$, который с изменениями формально действовал свыше 50 лет. Следует согласиться с доктринальными утверждениями о том, что «годы нэпа по своему внутреннему наполнению во многом схожи со становлением и развитием рыночных отношений в Российской Федерации 1990-2000-х гг.» и что «не случайно некоторые нормы данного кодекса перешли в современное трудовое законодательство» ${ }^{3}$.

Нельзя также отрицать тот фракт, что по мере ужесточения внутренней политики и перехода на форсированное развитие страны значительная часть его норм перестала применяться, даже будучи формально не отмененными (по устоявшейся традиции советского законодателя, если не отменялось, то существенно корректировалось соответствующими распоряжениями или постановлениями).

Так, редакция КЗоТ 1922 г. изначально предполагала обязательное взаимодействие в процессе приема на работу работодателя и биржи труда, однако в 1925 г. это положение было отменено постановлением ЦИК и СНК СССР от 2 января 1925 г. «О порядке найма рабочей силы» ${ }^{4}$

С принятием КЗоТ 1922 г. трудоустройство стало добровольным, а привлечение к труду допускалось лишь в исключительных случаях. Согласно ст. 11 в случае стихийных бедствий или недостатка рабочей силы в процессе выполнения важнейших государственных заданий все граждане РСФСР, кроме выделенных законодательно категорий, могли быть привлеченными к труду в порядке отработки трудовой повинности. Тем не менее законодательно также устанавливалась чрезвычайность указанной меры.

Важно подчеркнуть, что особенностью рассматриваемого периода является появление в составе занятого населения категорий «наемных работников» и «предпринимателей».

В отношении последних необходимо пояснить, что Декретом ВЦИК и СНК РСФСР от 7 июля 1921 г. «О кустарной и мелкой промышленности» было закреплено право любого гражданина свободно заниматься кустарным промыслом и по достижении 18 лет создавать одно мелкое промышленное предприятие (МПП)

Под категорию МПП подпадали предприятия с персоналом до 20 наемных рабочих, «включая и работающих у себя на дому». Собственники

${ }^{2}$ О введении в действие Кодекса законов о труде Р.С.Ф.С.Р. : постановление ВЦИК от 9 ноября 1922 г. // СУ РСФСР. 1922. № 70. Ст. 903.

${ }^{3}$ См.: Давидян Г. М. Секреты долголетия КЗоТ 1922 г. // Трудовое право в России и за рубежом. 2017. № 2. С. 20-23.

${ }^{4} \mathrm{O}$ порядке найма рабочей силы : постановление ЦИК и СНК СССР от 2 января 1925 г. // Собр. законодательства СССР. 1925. № 2. Ст. 15 ; Шащенко А. Н. Государственно-правовое регулирование занятости населения России в 1917-1925 гг. : историко-правовое исследование : автореф. дис. ... канд. юрид. наук. Курск, 2013.

${ }^{5}$ СУ РСФСР. 1921. № 53. Ст. 323. 


\section{Вестник ВГУ. Серия: Право}

МПП, где использовался наемный труд, регистрировали свои предприятия в местных Совнархозах. Регистрация имела заявительный характер. Кустари и ремесленники, равно как и владельцы МПП, были обязаны соблюдать трудовое законодательство. МПП, их имущество могли быть реквизированы или конфискованы по решению суда на основании особых постановлений СНК ${ }^{6}$.

Следует также упомянуть, что в тот период существовал хотя и не многочисленный, но частный сектор в сфере здравоохранения.

Частное здравоохранение было разрешено постановлением СНК РСФСР от 9 января 1922 г. «Об открытии частных лечебных заведений и аптек» ${ }^{7}$, а частная практика - декретом ВЦИК и СНК РСФСР от 1 декабря 1924 г. «О профессиональной работе и правах медицинских работников» 8

Вместе с тем негативным явлением на рынке труда 20-х гг. была безработица. Прямым образом сказались на количестве занятой рабочей силы такие факторы, как разрешение частной собственности и введение хозрасчета, основанного на коммерческой выгоде с точным учетом всех расходов и себестоимости продукции.

Переход на самоокупаемость сопровождался массовыми сокращениями штатов, в результате чего значительное число людей осталось без работы. О темпах роста безработицы можно судить, исходя из следующих данных. Так, в начале 1922 г. было зарегистрировано 160 тыс. безработных; на 1 января 1923 г. их число составило 641 тыс., а к 1 января 1924 г. число безработных достигло 1 млн 240 тыс. $^{9}$

В наибольшей степени, безработица коснулась таких социально-профессиональных групп, как рабочие.

Например, на 1 июля 1925 г. число безработных составило среди индустриальных рабочих 28,8 \%; лиц интеллигентского труда $-23,3$ \%; чернорабочих $-36,1 \%{ }^{10}$.

По всей стране активно фрункционировала сеть бирж труда ${ }^{11}$, ставших главными информационно-координирующими органами, осуществляющими трудоустройство ${ }^{12}$. Особенность начального этапа работы бирж

${ }^{6}$ Подробнее см.: Селенова Т. А. Правовое регулирование самостоятельной занятости. М., 2017. С. 60.

${ }^{7}$ СУ РСФСР. 1922. № 6. Ст. 58.

8 Там же. 1930. № 4. Ст. 45.

${ }_{9}^{9}$ См.: Гилмельббарб С. Ликвидация безработицы в СССР и проблема кадров // Проблемы экономики. 1931. № 4/5. С. 31.

${ }^{10}$ См.: Никольский Н. Безработица и ее перспективы // Вопросы труда. 1925. № 10 . C. 9.

1127 января 1918 г. СНК было принято «Положение о биржах труда» // Декреты советской власти. М., 1957. Т. 1. С. 424-426.

${ }^{12}$ В течение 1923-1925 гг. биржи труда были созданы во всех губернских городах и районах с большим скоплением безработных. К 1926 г. в стране насчитывалось 256 бирж труда, в городах, где было менее 500 безработных, создавались корреспондентские пункты, и их насчитывалось более 1000 (см.: Рогачевская Л. С. Ликвидация безработицы в СССР. М., 1973. С. 95-96). 
труда состояла в том, что безработные, желающие получить работу, и работодатели, имеющие в распоряжении свободные рабочие места, обязывались регистрировать в этих учреждениях свои предложения и спрос на необходимых работников. Подбор работников, минуя биржи, запрещался. Был организован специальный штат агентов и инспекторов, которые обследовали предприятия и организации для установления фрактов незаконного приема на работу. В то же время в случае беспричинного отказа принять работника, направляемого биржей, наниматель привлекался к ответственности ${ }^{13}$. Важным шагом в деле регулирования трудового рынка стало введение практики заключения трудовых договоров при устройстве на работу, устанавливавших конкретные условия найма, что стало новеллой в сравнении с политикой военного коммунизма ${ }^{14}$.

Постоянно продолжалось привлечение рабочей силы из сельской местности.

В связи с этим 24 января 1925 г. НКТ РСФСР и НКВД РСФСР приняли постановление «О возложении на волисполкомы и сельсоветы обязанностей по наблюдению за наймом в деревне массовой рабочей силы из числа местного крестьянского населения для работы вне места жительства» ${ }^{15}$.

На волисполкомы и сельсоветы возлагалась обязанность наблюдать за проведением набора рабочих и действиями вербовщиков, проверять их полномочия, пресекать нарушения правил вербовки и частное посредничество и вербовку.

10 марта 1926 г. НКТ РСФСР утвердил «Положение о корреспондентских пунктах по регулированию отхода на промыслы» и «Положение о трудовых корреспондентах в сельских местностях» ${ }^{16}$.

В соответствии с этими нормативными актами в сельских местностях создавались корреспондентские пункты и сеть трудовых корреспондентов для учета отходников, указания им мест работы для предупреждения массового наплыва безработных в города, для ведения совместно с биржами труда информационной работы о развертывании нового строительства, о наличии спроса на работников в различных губерниях и областях ${ }^{17}$.

Для повышения эфрфективности работы бирж труда уже в 19231924 гг. начало широко практиковаться проведение экспертизы для более точного определения и проверки профессиональных знаний и навыков, специализации рабочих и служащих, ищущих работу.

${ }^{13} \mathrm{O}$ порядке направления ищущих труда на работу на биржи труда : инструкция Наркомата труда от 13 августа 1923 г. № 27 // Вестник труда. 1923. № 8. С. 296.

${ }^{14}$ Собранение узаконений и распоряжений Рабочего и Крестьянского правительства. М., 1922. № 70. С. 903.

${ }^{15}$ Известия НКТ СССР. 1925. № 27. С. 2 ; № 28. С. 3.

16 Там же. 1926 . № 14. С. 2-3.

${ }^{17}$ См.: Фоббанова Н. П. Трудовое посредничество в России : проблема ликвидации безработицы в советский период // История государства и права. 2008. № 14. Доступ из справ.-правовой системы «КонсультантПлюс». 
В 1924 г. усиливается внимание к проведению практических испытаний. Постановление НКТ труда от 4 июля 1924 г. «О практическом испытании безработных» ${ }^{18}$ в целях осуществления правильного подбора по спросу предусматривало практическое испытание безработных в тех случаях, когда профессия и специальность не могли быть в достаточной степени подтверждены документальными данными. Гражданам, прошедшим практическое испытание, выдавалось на руки удостоверение о проделанной работе ${ }^{19}$.

Всероссийское совещание работников бирж труда, которое состоялось в Москве в октябре 1924 г., высказалось за необходимость перехода работы бирж труда на новые начала. Совещание констатировало, что действующая система снабжения промышленности рабочей силой, основанная на принципах обязательного найма через биржи труда, вступает в противоречие с тенденцией развития народного хозяйства и кампанией по повышению производительности труда. В резолюции совещания говорилось о целесообразности упразднения обязательности найма через биржи труда для всех категорий безработных ${ }^{20}$.

Нарком труда РСФСР В. В. Шмидт в докладе на IV съезде профсоюзов СССР отмечал: «...если мы дальше будем работать теми методами, которыми работали до сих пор, т. е. устанавливая обязательность найма только через биржи труда и устанавливая внутри бирж такой порядок, что в первую очередь посылаются на работу те, кто стоит или кто ранее зарегистрировался на бирже труда, то, конечно, мы никогда не будем в состоянии правильно регулировать рынок труда и не получим... действительной картины безработицы» ${ }^{21}$.

В 1925 г. обязательность найма рабочей силы через органы НКТ была отменена. Все заключаемые с работодателями сделки по найму трудящихся подлежали лишь обязательной последующей регистрации в посреднических органах 22 .

В целях ускорения подготовки и обучения необходимой для промышленности квалифицированной рабочей силы постановлением ЦК ВКП (б) от 11 марта 1926 г. «О подготовке и обучении рабочей силы» ${ }^{23}$ было предусмотрено проведение ряда мероприятий, в том числе подготовка квалифицированной рабочей силы с учетом потребностей конкретных пред-

${ }^{18}$ Известия Народного комиссариата труда. 1924. № 25-26.

${ }^{19}$ См.: Мохов 3. Наш опыт в области подбора и подготовки рабочей силы // Вопросы труда. 1925 . № 5/6. С. 22 ; Стряпихина A. А. Биржи труда и особенности трудоустройства в СССР в 1920-е гг. // Ученые записки Новгородского гос. ун-та имени Ярослава Мудрого. 2018. № 6(18). С. 2.

${ }^{20}$ См.: Стряпихина А. А. Указ. соч. С. 2 ; Бахусов А. Итоги совещания работников бирж труда // Вопросы труда. 1924. № 11. С. 27.

${ }^{21}$ Шлидт В. Доклад на VI съезде профессиональных союзов СССР // Вопросы труда. 1924. № 11. С. 12.

${ }^{22}$ См.: Хроника отдела рынка труда // Вопросы труда. 1925. № 1. С. 155.

${ }^{23}$ Решения партии и правительства по хозяйственным вопросам. М., 1967. T. 1. C. 512-514. 
приятий; предусматривались различные формы обучения и, наряду с фрабрично-заводскими краткосрочными курсами, бригадное и индивидуальное ученичество на производстве, переквалификация безработных и т. д.

Позднее в резолюции XV конференции ВКП(б) от 3 ноября 1926 г. «О хозяйственном положении страны и задачах партии» отмечалось, что «последние годы характеризуются бурным ростом количества занятых рабочих» ${ }^{24}$. Наряду с этим конференция отмечала ухудшение качества работы в связи с вовлечением значительных кадров малоквалифицированных рабочих, нерациональным использованием рабочей силы, ослаблением трудовой дисциплины. На конференции были также озвучены меры, направленные на снижение роста числа безработных из-за прибывшего в города сельского населения: «...во-первых, такие мероприятия в самом сельском хозяйстве, которые увеличили бы его потребность в рабочей силе (помощь деревенской бедноте, усиление трудоемких культур, интенсификация сельского хозяйства, коллективизация его, переселение и т. п.) и, во-вторых, развитие индустрии, одновременно с этим должны были быть приняты немедленные меры по расширению общественных работ, упорядочению в помощи безработным, найма и увольнения рабочих и организации бирж труда» ${ }^{25}$.

Однако сокращение государственного вмешательства в дело регулирования рынка труда ставило под сомнение осуществление намеченных планов промышленного развития. И вновь возникла острая необходимость усиления государственного контроля в области привлечения и распределения рабочих кадров.

В постановлении ЦИК и СНК СССР от 4 марта 1927 г. «О мерах по регулированию рынка труда» ${ }^{26}$, в частности, указывалось, что «набор массовой и групповой рабочей силы должен производиться всеми государственными, общественными и частными учреждениями и предприятиями не иначе как на основании заблаговременно заключенных ими с Наркомтрудом СССР, Наркомтрудом союзных республик и их местными органами специальных соглашений» ${ }^{27}$.

Постановлением СНК СССР от 11 апреля 1927 г. «О мероприятиях по регулированию вербовочных операций» ${ }^{28}$ предусматривалось, что если набор рабочих производится непосредственно хозорганом, то должны быть определены районы, срок вербовки, количественный набор рабочих. Этот нормативный акт обязывал органы труда осуществлять планирование районов найма и вербовку рабочих по соглашению с хозорганом. Однако органы труда не располагали необходимым вербовочным

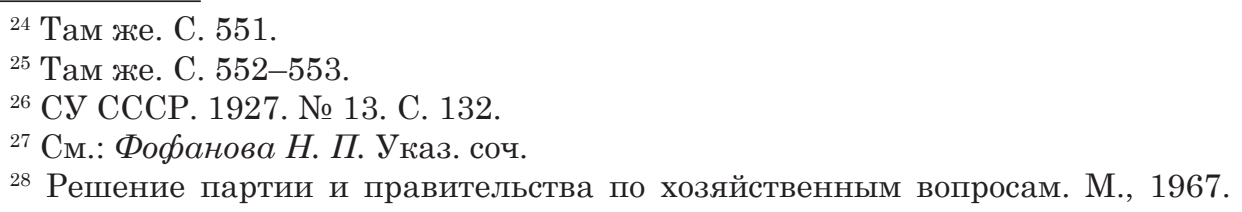
T. 2. C. $648-650$. 


\section{Вестник ВГУ. Серия: Право}

аппаратом. Вся работа по вербовке проводилась вербовщиками хозорганов при плохом планировании районов. Отсутствие единых расценок на однородные работы приводило к межведомственной конкуренции и срывало наём рабочих ${ }^{29}$.

Несмотря на усилия государства в деле обеспечения занятости в 1926-1928 гг. возможность трудоустройства безработных была всё еще ограничена, так как новое промышленное строительство в эти годы было небольшим. Число фрабрично-заводских предприятий увеличилось всего на 384 (с 8516 в 1926 г. до 8900 в 1928 г.) ${ }^{30}$. Проблема решалась путем предоставления соответствующих мер социальной поддержки безработным: организации общественных работ ${ }^{31}$, выплаты пособия по безработице ${ }^{32}$, оказании иной помощи ${ }^{33}$.

Говоря об общественных работах, следует упомянуть, что подход к их организации и фринансированию в разные годы нэпа был неоднозначным.

В 1921-1923 гг. организация общественных работ происходила стихийно, что объяснялось недостатком денежных средств, поскольку их организация осуществлялась и фринансировалась хозяйственными органами, которые проводили эти работы.

Как отмечено в литературе, в этот период общественные работы проводились в Симферопольском, Севастопольском, Донском, Феодосийском, Ялтинском, Евпаторийском, Керченском округах.

Такая мера поддержки безработных активно применялась в Ленинграде, Москве, Минске, а также в Витебской, Самарской, Тверской, Полтавской, Одесской, Николаевской губерниях ${ }^{34}$.

В общей сложности в 1922-1923 гг. на организацию общественных работ было отпущено 1 млн 200 тыс. рублей золотом ${ }^{35}$.

${ }^{29}$ См.: Фоббанова Н. П. Указ. соч.

${ }^{30}$ Статистика труда. 1928. № 7. С. 1.

31 О порядке организации и проведения общественных работ : инструкция НКТ РСФСР от 2 марта 1927 г. // Известия НКТ СССР. 1927. № 21.

32 Пособие для безработных квалифицированных рабочих и работников умственного труда (имевших среднее и высшее образование) было установлено на VII съезде профсоюзов (1927 г.) в размере 33 \% от средней заработной платы в данной местности; для полуквалифицированных рабочих - 25 \%; неквалифицированных 20 \%. Квалифицированным рабочим пособие выдавалось в течение 9 месяцев, остальным категориям безработных - в течение 7 месяцев. Особо нуждавшиеся безработные получали бесплатные обеды. В 1922 г. в некоторых местах безработным выдавался месячный паек. В 1926-1930 гг. пособие по безработице получили 2473 тыс. человек (подробно см.: Сычева А. С. Как была ликвидирована безработица в СССР // Вопросы истории. 1967. № 2. С. 3 ; Труд в СССР. М., 1930. С. 71).

${ }^{33}$ Об обеспечении безработных : декрет СНК от 3 октября 1921 г. // СУ РСФСР. 1921. № 68. Ст. 536 ; О предприятиях и коллективах, организуемых комитетами бирж труда для оказания трудовой помощи безработным : постановление ВЦИК и Совнаркома РСФСР от 23 марта 1923 г. // Там же. 1923. № 11. Ст. 56.

${ }^{34}$ См.: Исаев А. Безработица в СССР и борьба с ней за период 1917-1924 гг. M., 1924. C. 60.

${ }^{35}$ См.: Там же. С. 63. 
В последующие годы усилилось государственное финансирование общественных работ, которое уже составляло ежегодно $12-15$ млн рублей ${ }^{36}$.

Основные виды общественных работ предусматривали очистку и ремонт улиц, устройство парков и т. д. В 1928-1929 гг. хозяйственные планы ряда отраслей промышленности предусматривали очистку территорий заводов, сортировку металлолома с тем, чтобы занять подобной работой часть безработных ${ }^{37}$.

На общественных работах безработный зарабатывал в среднем за один день, например в Москве, 1 руб. 50 коп., в Ленинграде - 1 руб. 25 коп. . $^{38}$

К 1928 г. появилась возможность перейти к твердому перспективному планированию распределения рабочей силы.

Удельный вес социалистического сектора к 1928 г. составлял в валовой продукции промышленности $82,4 \%$; в розничном товарообороте торговых предприятий $-76,4$ \%; в фабрично-заводской промышленности в 1925-1926 гг. - 2678 тыс. рабочих, в 1926-1927 гг. - 2838 тыс., в 1927-1928 гг. - 3033 тыс. и в 1928-1929 гг. - 3266 тыс. Таким образом, в 1926-1928 гг. происходил постоянный рост числа рабочих. По предварительным подсчетам госплана, число безработных должно было снизиться за пятилетие (1927-1928 - 1932-1933 гг.) с 1,1 млн человек до 800 тыс. Оптимальный вариант плана сводил этот остаток примерно до 400 тыс. человек. Но такое планирование не могло быть всеобъемлющим, так как удельный вес социалистического сектора в сельском хозяйстве был еще невелик ${ }^{39}$.

В последние годы нэпа усилилась атака государства на частную и индивидуально-трудовую инициативу. Уже к 1928 г. число частных промышленных предприятий сократилось почти вдвое. В основном это касалось частных пекарен, разного рода мастерских, кондитерских и т. п. В это же время число частных магазинов и лавок сократилось на $40 \%$ и продолжало сокращаться. Удельный вес торговли в совокупном торгово-посредническом обороте СССР в 1928-1929 гг. упал вдвое ${ }^{40}$.

В свою очередь, резолюция по развитию нового «индустриального» типа здравоохранения не оставила места частной практике. Частный медицинский сектор, по официальной статистике того времени ${ }^{41}$, постепенно ликвидировался, переходя в «тень», сохраняя легальные позиции лишь в сфере зубопротезирования ${ }^{42}$.

${ }^{36}$ Народное хозяйство СССР. Статистический сборник. 1956. С. 31.

${ }^{37}$ См.: Съчева А. С. Указ. соч. С. 30.

${ }^{38}$ См.: Гиндин Я. И. Регулирование рынка труда и борьба с безработицей // Вопросы труда. 1928. С. 132.

${ }^{39}$ См.: Там же С. 32.

${ }^{40}$ См.: Делчик E. B. Частный капитал в городах Сибири в 20-е годы : от возрождения к ликвидации. Барнаул, 1998. С. 180-181.

${ }^{41}$ Статистический обзор состояния здравоохранения и заболеваемость заразными болезнями в РСФСР в 1927 г. М. ; Л., 1931.

${ }^{42}$ См.: Селенова T. А. Указ. соч. С. 72. 
К концу периода нэпа в плановое и организованное русло вводилось все перемещение трудовых резервов из деревни в промышленность. С победой социалистического сектора как в промышленности, так и в сельском хозяйстве планомерное распределение рабочей силы стало основной формой трудоустройства рабочих и служащих. Биржи труда были реорганизованы в управления кадров, на которые возлагалось плановое распределение рабочих, а также планирование и контроль за подготовкой рабочих кадров.

Таким образом, переход к нэпу (при обозначении государством временных компромиссов - пределов допущения частной экономической инициативы, которые четко регламентировало действующее в то время законодательство) стал важнейшим стимулом в развитии сферы обслуживания, торговли, общественного питания и т. д.

Позитивные начала, заложенные в принятом в 1922 г. КЗоТ и иных актах, регулирующих сферу занятости, отвечали кардинальным переменам в правовой, политической и экономической политике советской России и, несомненно, оказали влияние на законодательство Российской Федерации в период развития рыночных отношений 1990-2000-х гг.

Так, поворотным в деле регулирования трудового рынка стало введение практики заключения трудовых договоров при устройстве на работу, устанавливавших конкретные условия найма. Обязательной мерой явилось требование для владельцев малых производственных предприятий соблюдать нормы трудового законодательства под угрозой конфискации собственности по решению суда на основании особых постановлений CHK.

В целях осуществления правильного подбора работников предусматривалось практическое испытание безработных в тех случаях, когда профессия и специальность не могли быть в достаточной степени подтверждены документальными данными. Гражданам, прошедшим практическое испытание, выдавалось на руки удостоверение о проделанной работе. И здесь, как представляется, явно прослеживается преемственность разработки и продвижения современной концепции оценивания квалификаций работников, закрепленной в ныне действующем российском законодательстве.

Сейчас под независимую оценку квалификации подпадают работники или лица, претендующие на осуществление определенной деятельности (соискатели).

Независимая оценка квалификации проходит в форме профессионального экзамена, который можно сдать в специальных центрах оценки квалификации (ч. 1 ст. 4 Закона № 238-ФЗ ${ }^{43}$ ), пройдя при этом довольно сложную процедуру и не во всех случаях безвозмездно. Принимая во внимание позитивный исторический опыт, представляется целесообразным на законодательном уровне закрепить создание в территориальных

${ }^{43} \mathrm{O}$ независимой оценке квалификации : федер. закон от 3 июля 2016 г. № 238-ФЗ // Рос. газета. 2016. 6 июня. 
органах службы занятости подразделений в составе соответствующих специалистов, в компетенцию которых входило бы проведение оценки квалификации граждан, претендующих на вакантную должность по направлению территориальных отделений службы занятости в случаях:

1) если квалификация лиц, обратившихся в службу занятости в целях поиска подходящей работы и претендующих на свободную вакансию по соответствующей должности (специальности), не в достаточной степени подтверждена документальными данными;

2) по инициативе потенциального работодателя или соискателя, при наличии у последнего документального подтверждения имеющейся у него квалификации, однако не в полной мере соответствующей требованиям профессионального стандарта.

Полагаем, что включение указанных положений в действующее законодательство (ч. 1 ст. 4 Закона № 238-ФЗ, ст. 195 ТК РФ) позволит:

- оптимизировать работу отделений службы занятости;

- избежать необоснованных отказов гражданам в трудоустройстве со стороны потенциальных работодателей;

- сделать эту услугу безвозмездной для соискателей.

Для периода нэпа характерна неоднократная корректировка политических решений в сфере регулирования рынка труда: от обязательного трудоустройства через биржевую сеть до отмены и последующего возобновления указанной процедуры. Это было обусловлено объективной необходимостью в силу ряда причин, вызванных потребностью обеспечения справедливости при трудоустройстве, ростом безработицы, перезагруженности работой бирж труда, а также отсутствием на начальном этапе отлаженного механизма подбора работников высокой квалификации. Несмотря на отдельные недостатки, оперативность в принятии решений и приобретенный в непростых условиях опыт по привлечению рабочей силы позволил государству создать и подготовить необходимые трудовые ресурсы для последующего этапа - проведения индустриализации страны.

Этому способствовала также практика обучения (переквалифрикации) безработных по недостающим специальностям для своевременного обеспечения новых строительных и хозяйственных объектов рабочими кадрами. Такой опыт, по нашему мнению, представляет особую ценность в плане преемственности и использования в современных условиях в рамках региональных программ содействия занятости. Особенно важна практика подготовка квалифицированной рабочей силы с учетом потребностей конкретных предприятий и организаций.

Опыт организации и фринансирования общественных работ как мера содействия занятости, равно как и практика выплаты пособия по безработице как вид материальной поддержки безработных граждан, не потеряли актуальности, найдя отражение в нормах ныне действующего законодательства. 


\section{Библиографический список}

Бахутов А. Итоги совещания работников бирж труда // Вопросы труда. 1924. № 11. C. 26-30.

Гимлельфарб С. Ликвидация безработицы в СССР и проблема кадров // Проблемы экономики. 1931. № 4/5. С. 23-56.

Гиндин Я. И. Регулирование рынка труда и борьба с безработицей // Вопросы труда. 1928.

Давидян Г. М. Секреты долголетия КЗоТ 1922 г. // Трудовое право в России и за рубежом. 2017. № 2. С. 20-23.

Демчик E. В. Частный капитал в городах Сибири в 20-е годы : от возрождения к ликвидации. Барнаул, 1998. 239 с.

Исаев А. Безработица в СССР и борьба с ней за период 1917-1924 гг. М., 1924. $79 \mathrm{c}$.

Мохов 3. Наш опыт в области подбора и подготовки рабочей силы // Вопросы труда. 1925. № 5/6. С. 21-30.

Никольский Н. Безработица и ее перспективы // Вопросы труда. 1925. № 10.

Рогачевская Л. С. Ликвидация безработицы в СССР. М. : Наука, 1973. $382 \mathrm{c.}$

Семенова Т. А. Правовое регулирование самостоятельной занятости. М. : Политическая энциклопедия. 2017. 263 с.

Стряпихина A. А. Биржи труда и особенности трудоустройства в СССР в 1920-е гг. // Ученые записки Новгородского гос. ун-та имени Ярослава Мудрого. 2018. № 6 (18). С. 1-5.

Стряпихина А. А. Государственная политика СССР в области занятости (20-е годы XX века) // Труд и социальные отношения. 2011. № 3. С. 91-95.

Сычева А. С. Как была ликвидирована безработица в СССР // Вопросы истории. 1967. № 2. С. 27-36.

Фоббанова Н. П. Трудовое посредничество в России : проблема ликвидации безработицы в советский период // История государства и права. 2008.

을 № 14. Доступ из справ.-правовой системы «КонсультантПлюс».

Шащенко А. Н. Государственно-правовое регулирование занятости населения России в 1917-1925 гг. : историко-правовое исследование : автореф. дис. ... канд. юрид. наук. Курск, 2013. 25 с.

\section{References}

Bakhutov A. Results of the meeting of employees of labor exchanges // Labor issues. 1924. № 11. P. 26-30.

Himmelfarb S. Liquidation of unemployment in the USSR and the problem of personnel // Economic problems. 1931. № 4/5. P. 23-56.

Gindin Ya. I. Labor market regulation and the fight against unemployment // Labor issues. 1928.

Davidyan G. M. Secrets of longevity of the Labor Code of 1922 // Labor law in Russia and abroad. 2017. № 2. P. 20-23.

Demchik E. V. Private capital in the cities of Siberia in the 20s: from Revival to Liquidation. Barnaul, 1998. 239 p.

Isaev A. Unemployment in the USSR and the fight against it for the period 1917-1924. M. : Questions of labor, 1924.79 p. 
Mokhov Z. Our experience in the field of recruitment and training of the labor force // Labor issues. 1925. № 5/6. P. 21-30.

Nikolsky N. Unemployment and its prospects // Labor issues. 1925. № 10.

Rogachevskaya L. S. Elimination of unemployment in the USSR. M. : Nauka, 1973. $382 \mathrm{p}$.

Semenova T. A. Legal regulation of self-employment. M. : Political Encyclopedia, 2017. 263 p.

Stryapikhina A. A. Labor exchanges and features of employment in the USSR in the 1920s. // Scientific Notes of the Yaroslav the Wise Novgorod State University. 2018. № 6 (18). P. 1-5.

Stryapikhina A. A. State policy of the USSR in the field of employment (20-e years of the XX century) // Labor and social relations. 2011. № 3. P. 91-95.

Sycheva A. S. Kak was liquidated unemployment in the USSR // History questions. 1967. № 2. P. 27-36.

Fofanova N. P. Labor mediation in Russia: the problem of eliminating unemployment in the Soviet period // History of state and law. 2008. № 14.

Shashchenko A. N. State-legal regulation of employment of the population of Russia in 1917-1925: historical and legal research: abstract of the dissertation of the candidate of Legal Sciences. Kursk, 2013. 25 p.

\section{Для иитирования:}

Павловская О. Ю. Правовые механизмы регулирования трудовой занятости в СССР в период новой экономической политики // Вестник Воронежского государственного университета. Серия: Право. 2021. № 3 (46). C. 88-99. DOI: https://doi. org/10.17308/vsu.proc.law.2021.3/3542

\section{Recommended citation:}

Pavlouskay O. Yu. Legal mechanisms for regulating labor employment in the USSR during the period of the new economic policy // Proceedings of Voronezh State University. Series: Law. 2021. № 3 (46). P. 88-99. DOI: https://doi.org/10.17308/vsu.proc. law.2021.3/3542

Национальный исследовательский университет "Высшая школа экономикu»

Павловская О. Ю., кандидат юридических наук, доцент

E-mail: olga_pavlovskay@hse.ru
National Research University "Higher School of Economics"

Pavlouskay O. Yu., Candidate of Legal

Sciences, Associate Professor

E-mail: olga_pavlovskay@hse.ru 